\title{
Experiences of sharing, learning and caring: Peer support in a Finnish group of mothers
}

Eija Eronen

Faculty of Social Sciences, Tampere University, Tampere, Finland

\begin{abstract}
Mothers' peer groups constitute a form of communal support that affords potential benefits but has received little attention in Finland. At present, only a few studies have investigated the support provided by peer groups of mothers. This article explores mothers' experiences of peer support in a Finnish peer group. First, the data gathered in 2015 comprise data from thematic interviews with 23 mothers participating in peer group activities. Second, the data include written notes gathered during participant observation in the group's 12 meetings, two outings and summer camp. The data were analysed by utilising a phenomenological-hermeneutic approach, and three themes representing mothers' experiences were identified: (1) sharing of experiences, (2) learning from experiences and (3) experiences of mutual caring. By exploring relationships among these themes, this study found that the sharing of experiences is a starting point for learning and caring among mothers. These findings suggest that the sharing of experiences is a crucial part of peer support because it results in learning and caring. Versatile support can be enabled by strengthening the preconditions for sharing.
\end{abstract}

Keywords: Peer support, peer group, self-help group, mothers, mother-child relationship, maternal welfare

\section{What is known about the topic:}

- Motherhood is a demanding stage in life, which can create a need for peer support.

- The need for support can be met by the activities of mothers' peer groups.

- Little is known about the support provided by peer groups of mothers. 


\section{What this paper adds:}

- Sharing of experiences among mothers brings about learning and caring in a peer group.

- Mothers seeking peer support are not necessarily able to share their experiences in a group.

- Versatile support can be enabled by strengthening the preconditions for sharing experiences in peer groups of mothers.

\section{Introduction}

Support between peers can be regarded as a special form of helping activity. Also referred to as mutual support and self-help (Boyce, Munn-Giddings, \& Secker, 2018), peer support is characterised by parties sharing an experience of similar conditions (Solomon, 2004). Sharing an experience can bring about an understanding that peers cannot otherwise obtain (Borkman, 1999, p. 198-199; Mead, Hilton, \& Curtis, 2001, p. 135; Munn-Giddings \& McVicar, 2007, p. 29). Moreover, sharing an experience creates a basis for equal and reciprocal relationships between peers; because they are in the same situation, they are potentially both givers and receivers of support (Smith, Drennan, Mackenzie, \& Greenwood, 2018).

Peer support is often described as the expression of experiences shared among interconnected parties (Munn-Giddings \& McVicar, 2007; Seebohm et al., 2013; Boyce et al., 2018). For decades, peer support has been related to the notion of sharing experiential knowledge. It is a question of knowledge based on personal experiences that peers convey to each other (Borkman, 1976). As shown in a range of studies on peer support, receiving knowledge has many positive effects. Gaining experiential knowledge can help to alleviate emotional drain, can help in learning practical skills and ways of coping, and can facilitate appropriate support outside of the peer relation (e.g., Borkman, 1999; Mead et al., 2001; Neale, Tompkins, \& Strang, 2018). 
The need for peer support can arise when a woman becomes a mother because of the strain induced by contradictory maternal experiences (Cronin, 2003; Choi, Henshaw, Baker, \& Tree, 2005; EllisSloan, 2015). It is known that mothers experience emotions of happiness and pleasure as well as loneliness and uncertainty. Caring for a child can feel deeply meaningful but also exhaustive and binding (Miller, 2005; MacDonald, 2010). It is not surprising, therefore, that some mothers seek to establish peer relations (Cronin, 2003; Choi et al., 2005; Ellis-Sloan, 2015). They desire opportunities to share their experiences with peers (Cronin, 2003) and to receive experience-based knowledge related to mothering (Choi et al., 2005).

The need for peer support is intertwined with the expectations that mothers face. In Western culture, mothers are typically expected to exhibit total selflessness and a full capacity for caring (Hays, 1996). These expectations further increase maternal strain (Tummala-Narra, 2009; Wall, 2010). As Rizzo, Schiffrin and Liss (2013) noted, a commitment to meeting such expectations can result in negative mental health outcomes. Such expectations make it hard to seek support, since talking about difficulties involves a risk of being stigmatised as a bad mother (Miller, 2005). Mothers are not necessarily able to speak about their experiences; rather, they may speak about what is expected of them (Choi et al., 2005; see also Friedman, 2013).

On the other hand, mothers can give and receive support by participating in groups in which they meet with peers. These peer groups are communities of participants that share similar experiences and are also known as self-help groups and self-help/mutual-aid groups (e.g., Munn-Giddings \& McVicar, 2007; Boyce et al., 2018). Unlike in groups led by a professional, the ownership and control of peer groups rest with their members. If professionals are involved, their role is to support the group according to the needs and wishes of its members (Oka \& Borkman, 2011; Munn-Giddings et al., 2016/17). The activity of these groups is self-organising and voluntary (Borkman, 1999), with a bottom-up approach (Nylund, 2000). 
In Finnish society, the peer group activity of mothers is largely disregarded as a communal resource. In contrast, plenty of interest has been directed towards national social welfare and health care, which are characterised by relatively wide-ranging coverage and funding based on tax revenues (Anttonen \& Sipilä, 2011). In Finland, as in other Nordic welfare states, mothers receive support from the public system of family services (Eydal \& Kröger, 2010; Sihvonen \& Sundsbø, 2018). According to national legislation, it is a matter of offering support to families for the upbringing and nurturing of a child (Health Care Act 2010; Social Welfare Act 2014). This support is provided by, for instance, municipal maternity clinics, child guidance and family counselling and family work. Because of cutbacks on services in recent decades, however, considerations for the provision of support have included the potential for mutual support among citizens (Julkunen, 2008).

This article reports on a study that explored mothers' experiences of peer support in the context of group activity. The study was carried out as part of a wider research project examining mothers' peer group activities. The research question was as follows: (1) How do mothers experience the peer support realised in a group? Mothers' experiences were investigated by analysing multiple types of data from a phenomenological-hermeneutic starting point. Thematic interviews with mothers who participated in the peer group were used to obtain primary data, and written notes gathered during participant observation were used as supplementary data. On the basis of this analysis, this article explores mothers' experiences and thus contributes to discussions about motherhood and peer support. To date, peer support has been examined extensively in different group contexts (e.g., Borkman, 1999; Munn-Giddings \& McVicar, 2007; Boyce et al., 2018) but has been explored less from the viewpoint of mothers. 


\section{Methods}

\subsection{Study design}

The study was carried out by applying hermeneutic phenomenology as a starting point (Heidegger, 1978; Gadamer, 2013). Phenomenology aims to describe human experiences as they are lived (Husserl, 1982). In contrast, hermeneutics strives for an interpretation of the expression and objectification of experiences (Gadamer, 2013). Thus, hermeneutic phenomenology concentrates on interpretative descriptions of experiences (van Manen, 1990; Laverty, 2003; Vagle, 2018). In this study, a phenomenological-hermeneutic approach was applied by listening to mothers' experiences in interviews, supplementing their interpretation with observations of group activity and capturing them by analysing multiple types of data.

\subsection{Study settings}

The study was conducted with a peer group of mothers in Finland. The group is an unregistered community that operates in the third sector. Its objective is to support motherhood by operating as a self-regulating group. In addition to mothers, volunteers and practitioners organise group activities. Practitioners with qualifications in social welfare and health care support mothers to maintain operations by, for example, arranging a place for group meetings. In addition, volunteers take care of the mothers' children during most activities. Furthermore, the group works in cooperation with national NGOs and the Christian parish.

The group meets weekly with the exception of school holidays. In addition, the group arranges outings and an annual summer camp. Meetings last approximately 2 hours, outings last 1 day at the most, and the camp lasts 5 days. During these, mothers take part in different activities, such as conversations, exercise and cooking. The group is open to any mother. Therefore, motherhood can be regarded as the only common denominator among the group members. It is possible to have a central role in group operations through group members and their networks. During the data collection, an average of 10 
mothers attended the meetings. The number of participants was slightly higher in outings and summer camps. As participation is voluntary, mothers typically have different levels of involvement in activities. Some mothers participate actively, whereas some mainly follow the operation and receive information from it via social media.

\subsection{Data}

First, the data consist of written notes gathered during participant observation. Participant observation was carried out between February and July 2015. The observation included involvement in the group's 12 meetings, two outings and summer camp. Observation was not solely a question of watching the group operations; instead, it was essential to participate in group activities (Jorgensen, 2015). This required flexibility and adaptation to the practices of the group (Watts, 2011; Hammer, Fletcher, \& Hibbert, 2017). Participation was carried out as actively as possible on the mothers' terms. Therefore, the level of participation in an activity varied depending on how much the mothers seemed to want to give space to an outside researcher. After each participation, observations and conversations with mothers were written down.

Second, thematic interviews with mothers participating in the group activities were included in the data. The interviews were carried out between February and September 2015, close to the observation period. Informants were recruited by presenting an oral and a written interview request to mothers in the course of the observations. In addition, practitioners conveyed the request to mothers who were not involved in the group activities at that time. The interviews examined their participation in the group operations through two themes formed on the basis of observations: (a) group activities and (b) support provided by the group. As is typical in phenomenological-hermeneutic inquiry, themes were examined dialogically, openly and conversationally (van Manen, 1990; Vagle, 2018). Plenty of openended questions were asked of the informants, such as "what has stuck in your mind about the group 
meetings?" The interviews were conducted in places of mothers' choosing, such as in their homes, and ranged from $35 \mathrm{~min}$ to $2 \mathrm{~h} 16 \mathrm{~min}$. All interviews were taped and transcribed verbatim.

\subsection{Analysis}

The phenomenological-hermeneutic analysis proceeded in two stages. In the first stage, the examined data were defined. After the author carefully familiarised herself with the dataset, extracts concerning mothers' experiences of peer support were selected from the corpus of transcribed interviews. The written notes were not defined, although they included other themes in addition to peer support. To understand peer support in context, it was essential to examine the written notes as a whole.

In the second stage, the selected interview data were examined by applying the thinking of van Manen (1990, pp. 92-95). Thematic statements were isolated from the data on the basis of differences in their content. Each statement consisted of one or more interviewees' turn to speak. Next, themes characterising the peer support experienced by the mothers were formed from statements on the grounds of their mutual similarities. When formulating themes, a comparison between interview data and written notes was made to support interpretation. Subsequently, the themes were compared with each other to identify the relationships between them. Finally, the themes and their mutual relationships were cross-checked with the interview transcriptions and written notes to ensure their consistency.

\subsection{Ethical considerations}

The study was conducted by following the guidelines of the Finnish Advisory Board on Research Integrity $(2009,2012)$. At every stage, the privacy and autonomy of the informants were taken into account. The group members agreed to participate in the study before it began. Information about the purpose and content of the study was provided to them. During the data collection, special attention was given to the discreet treatment of mothers. Each of them gave informed consent prior to the 
interviews. Under the guidelines of the Finnish Advisory Board on Research Integrity, formal research ethics approval was not required (2009).

\section{Findings}

Some of the mothers involved in the group activity took part in the interviews $(\mathrm{N}=23)$. All of them were native Finnish women. Mothers had participated in the group activities from 4 months to 20 years, with an average of 7.5 years. In the course of data collection, 9 of them were involved in the group operation. All of the mothers had at least one child below school age when they joined the group. Some of them lived in a relationship with the father of the children or with a new partner. Some mothers had social networks outside the group, whereas some mentioned having insufficient support networks. Many mothers indicated that they had completed only basic education and did not work, whereas some reported working or being students.

As a result of the phenomenological-hermeneutic analysis, three themes representing mothers' experiences were identified: (1) sharing of experiences, (2) learning from experiences and (3) experiences of mutual caring. An exploration of the relationships among the themes revealed that the sharing of experiences was a starting point for learning and caring among the mothers (see Fig. 1). In the following section, the findings are examined in more depth and illustrated with interview extracts. When the extracts are presented, the names are replaced with pseudonyms, explanatory text added by the author is indicated by square brackets, and omitted non-relevant material is represented by dashes. Written notes are also utilised in the illustration and are marked as WN.

\subsection{Sharing of experiences}

The first theme illustrates the sharing of experiences. This means expressing experiences to group members according to the mothers' needs. Frequently, it involves open expression but occasionally involves refraining from doing so. It was often interesting to observe how naturally the mothers would both speak and be quiet (WN). The openness and confidentiality of the group atmosphere also became 
apparent when one of the mothers recounted the starting circle, which is part of the group's summer camp tradition:

Well, then we had that starting circle there. Then, everyone got the opportunity to tell their life stories if they wanted to, and I guess nobody ever thought about why they are speaking. - One could speak there and be heard by everyone. (Maria)

The sharing of experiences involved talking about everyday caring for children and the feelings related to it. Typically, this sharing involved an unembellished description of mothering without concealing the feelings, such as tiredness, that are connected with it (WN). It would be difficult to be so open if motherhood did not unite the group members. As one mother stated, "a person who isn't in that life situation is not interested in listening" (Fiona). However, at the same time, the mothers also noted that trust is essential in being understood by others. As one of them described:

There [in the group], one can have a moan because others understand. They don't just think that you're a bad mother, that you chose to become a mother so you should take care of your children. (Nina)

Most likely because of this trust, group members voiced their willingness to take a break from their maternal role. This desire is not solely a matter of maternal tiredness but also speaks to their role as women with needs of their own. Many mothers emphasised that they do not want to merely talk about their children. By contrast, they find it important to "really speak about something else" (Erin). Some mothers stated that they want to avoid talking about their children entirely, as indicated in the following extract:

I'm always with my children, and I speak only to these children, so now when I have adult company, I don't want to talk about children or anything related to children. And then somehow, the group was so good in that there were mothers as tired as I was. They were also like, yeah, we don't want to talk about children now since we just got rid of them for two hours [in a meeting]. (Ada)

Comparable sharing of experiences is not necessarily possible in other surroundings. Some mothers talked about having sought peer support elsewhere, such as in other groups. They recounted how they 
fell into self-censorship and embellishment of their experiences at that time. According to the group members, no one in those other groups spoke realistically about what it was like to be a mother; the conversations remained at a superficial level. As one mother pointed out:

If I can make a comparison, I have gone and attended other clubs or meetings. They have seemed much like those elite groups, where children are prettily dressed and they talk about some nice topic of the day, not really about the real everyday life in a family with children. In my opinion, this group goes deeper. (Emma)

Thus, many mothers indicated that an opportunity to share experiences in accordance with personal needs is a special characteristic of the group. According to them, it is also related to the freedom to act "simply like oneself" (Heidi), which might be difficult to achieve otherwise. As one mother stated, "sometimes it also goes differently, that you think in situations where you can speak and act like that, and then you realise that maybe it's not OK here" (Eva).

\subsection{Learning from experiences}

The second theme describes learning from experiences. When mothers share their experiences, they bring out knowledge based on their life experience. They share experiential knowledge and thus provide learning opportunities for others. Thus, in group settings, knowledge is conveyed continually, without being particularly asked for (WN). What is shared about experiences of motherhood might be invaluable knowledge for listeners, as illustrated in the following extract:

There are people who have a plenty of experience. Like mothers of several children who are little bit older than I am, people who really are in the know. And in the camp, I chatted with one mother about those parenting issues, so I gained plenty of info and tips like that. (Ella)

The mothers described how learning manifests as changes in ways of thinking. Some of them recounted how they came to regard themselves as mothers in a new way. They stated that the group had helped them to adopt a more permissive attitude than before. While listening to the experiences of others, the mothers might have noticed that those experiences are similar to theirs. Consequently, 
potential feelings of shame, guilt and isolation were eased, and it was more difficult to think of themselves as bad mothers. As one mother stated:

Maybe the most important thing for me has been that Daniel [child] was terribly defiant; he went from zero to one hundred. Well, then, when I left home, where I battled alone with him [child], and went there [group meeting], I noticed that, oh, here are twenty other children who get outbursts of rage. That my son is not abnormal at all, and I'm not a bad mother at all. (Emma)

The development of a new attitude also becomes possible when mothers' experiences are different from each other. Some mothers said they noticed that the experiences of others felt heavier than their own. Therefore, they came to experience their own situation as easier than before. At the same time, their sense of themselves might have changed. For instance, perceiving oneself as a bad mother is difficult to maintain when one notices that other mothers have even more challenging problems. As one mother ironically described:

When I think that I'm the only one who shouts at my children, then, I realise that someone else shouts even more. So really, I notice that other mothers are wrestling with similar or even much, much more serious things. (Sarita)

Learning is also a matter of changing one's actions. By listening to experiences, mothers can assess whether the strategies of other group members could be helpful to them as well. Some of them recounted that they had thus learned new ways to act as a mother. In some cases, they viewed group members as role models who showed examples of "how these things must be handled" (Alina). In other cases, they interpreted others' stories as providing "warning examples" (Jenna) about unsuitable practices. As one mother stated:

Like you see what kind of mothers there are. You see that I don't want to act in this way; I can take action like this. (Eva)

Strategies learned from the group might also provide a foundation on which to base actions. Some mothers recounted that they wanted to abandon the strategies learned from their childhood home but that they did not have other mothers in their circle of acquaintances. In that case, strategies learned 
from the group had been the only ones that the mothers could employ. As one of them described, peer support had resulted in the perception that "I probably learned, like, everything through this group" (Emma).

\subsection{Experiences of mutual caring}

The third theme depicts experiences of mutual caring. While sharing experiences, the mothers also talked about their need for help. Many of them expressed their needs while telling other stories, often openly and unashamedly (WN). By doing so, the mothers also give others an opportunity to provide help. Making the need for help visible creates space for mutual caring among mothers. This is illustrated in the following extract, in which one mother describes the sharing of experiences to enable caring:

If someone is lacking something, it is mentioned. So maybe it is that kind of helping and supporting. - Because these things are, like, kind of open so that people broadly know that, the situation the other has. (Anna)

The caring described by the mothers includes concrete help with childcare, which is definitely part of the group activities. Mothers talked about giving a great deal of help to each other when voluntary carers were not present. During the observations, it was occasionally impossible to distinguish who was the mother of whom (WN). At the same time, help was understood as care provided not only for children but also for the mothers themselves. This became apparent when one mother described the help with childcare obtained in the summer camp:

If there was some mother who was really like not doing well or had, like, let's say, stayed awake all night or something, then help was easily provided there, like "give the child here, and we'll go out so you can sleep or something." Of course, there were childminders too, but yeah, help was given, and help was also received when needed. So, it really was that kind of community. (Hanna)

Helping with childcare provides space for the experience of being cared for. This need can be fulfilled when another mother temporarily takes one's child. It is a matter of participating, for instance, "if 
there is something going on with a child, change his nappy or [offer] some other help" (Alina). Thus, the mother receiving help can rest. This type of help results in the experience of being cared for by other mothers. As one of them described, this experience provides an opportunity to feel maternal solicitude:

Really, they [other group members] treat me, like, in a very motherly way. They notice me and help with the children. When we are at the camp or outing or, or in the meeting, if somebody sees that I am having a horrible time with one child, they are ready to come and help me. So, there are, like, lovely people indeed. (Eva)

A similar experience of caring also becomes possible when mothers provide a different type of help to each other. Some of them describe how their mutual help with childcare is also realised at the material level. This help involves giving and receiving goods that are necessary for children (WN). Some mothers captured the meaning of that kind of care when they were unable to obtain these goods themselves. Care obtained from the group members provides protection when one lacks material resources. As one mother stated:

And it is like, if there is something lacking. For instance, the child is missing a bike or something like that, and you don't have any money at all. Then, you know that you can always ask for help. (Linda)

As illustrated above, caring is accompanied by the awareness that care is available when needed. This also became evident when one mother who participated in the group looked back on the mutual caring of mothers. She talked about having received care and trusting that she would also receive it in the future, for instance, during future pregnancies or children's illnesses. Therefore, she felt that the group was a place where "each person gets help" (Julia).

\section{Discussion}

This article explored mothers' experiences of peer support realised in a group. It discussed three themes representing their experiences: (1) sharing of experiences, (2) learning from experiences and (3) experiences of mutual caring. By examining the relationships among themes, this study found that 
the sharing of experiences is a starting point for learning and caring among mothers. Mothers share their experiences, resulting in learning and caring among them.

First, in line with previous studies (Munn-Giddings \& McVicar, 2007; Seebohm et al., 2013; Boyce et al., 2018), the findings emphasise the meaning of sharing experiences. The mothers participating in this study recounted that they were able to express their experiences according to their needs and by defying the idealised expectations that they face (Hays, 1996). It is noteworthy that the meaning of their common experience emerged through narration (see also Smith et al., 2018). However, they also indicated that solely sharing an experience of motherhood is not enough. The current study found that mothers may also feel that they have to embellish and censor their experiences in a group (see also Choi et al., 2005). This situation was one where they had sought peer support outside the group, where they found the discussions between mothers to be superficial. Apparently, these situations lacked the level of trust that probably allowed the mothers in the focal group to act contrary to expectations about coping and capability.

Second, the findings provide insights into learning between mothers. The mothers involved in the study recounted that they gained experiential knowledge and opportunities for learning from each other. In this regard, the findings support previous research reporting on the learning effects of peer support (Borkman, 1999; Mead et al., 2001; Neale, Tompkins, \& Strang, 2018). Furthermore, the findings deepen the current understanding by concentrating on learning among mothers. In the study, the mothers recounted that they had learned to be more forgiving of themselves and to try new strategies with their children. It can therefore be assumed that learning among peers can alleviate the strain associated with motherhood and the idealised expectations related to it (Tummala-Narra, 2009; Wall, 2010; Rizzo et al., 2013).

Third, the findings provide insight into caregiving between mothers. The mothers in the study showed that sharing experiences gave them an opportunity for concrete help. They gave and received help by 
caring for each other's children when they were not with the voluntary childminders. The findings thereby supplement our understanding of concrete help; this topic has received little attention in the literature on peer support, which has tended to concentrate on emotional support (e.g., MunnGiddings \& McVicar, 2007; Seebohm et al., 2013; Boyce et al., 2018). Furthermore, the study illustrated how providing childcare is experienced as caring directed towards mothers. Thus, providing concrete help can also be a way to provide emotional support. This is an important observation given the previously reported maternal burden of care (Miller, 2005; MacDonald, 2010), suggesting that peer support can lighten the strain related to care at both the tangible and emotional levels.

However, some limitations need to be taken into consideration when exploring the findings. First, this was a small-scale qualitative study carried out in Finland in a particular peer group setting. It is essential to recognise that the Finnish context and special characteristics of the explored group presumably influence the findings. Moreover, the interviewees had participated in the group for an average of 7.5 years, and the majority of them were in a socio-economically weak position. It is probable that the findings are confined to representing the experiences of mothers whose needs have been met in such a group and that several of them likely knew each other well. Therefore, further work is needed to examine peer support from the viewpoints of different groups of mothers.

Despite its limitations, the study has provided in-depth insights into mothers' experiences based on rich data and thus broadened our understanding of peer support. Moreover, the research findings can be applied in the practices of mothers' peer groups. In that sense, it is reasonable to take notice of special characteristics of the explored group that presumably created a trusting atmosphere enabling sharing experiences. Most likely, mothers were able to speak freely because, first, their children were with the childminders most of the time. Furthermore, the mothers themselves had authority over the operation - thus, they also decided what is spoken and how it is spoken in the group. 


\section{References}

Anttonen, A., \& Sipilä, J. (2011). Suomalaista sosiaalipolitiikkaa [Finnish social policy] (3th ed.). Tampere, Finland: Vastapaino.

Borkman, T. J. (1976). Experiential knowledge: A new concept for the analysis of self-help groups. Social Service Review, 50, 3, 445-456. doi: 10.1086/643401

Borkman, T. J. (1999). Understanding self-help / mutual aid: Experiential learning in the commons. New Brunswick, NJ: Rutgers University Press.

Boyce, M., Munn-Giddings, C., \& Secker, J. (2018). “'It is a safe space': Self-harm self-help groups”. Mental Health Review Journal, 23, 54-63. doi: 10.1108/MHRJ-06-2017-0021

Choi, P., Henshaw, C., Baker, S., \& Tree, J. (2005). Supermum, superwife, supereverything: Performing feminity in the transition to motherhood. Journal of Reproductive and Infant Psychology, 23, 167-180. doi: 10.1080/02646830500129487

Cronin, C. (2003). First-time mothers - Identifying their needs, perceptions and experiences. Journal of Clinical Nursing, 12, 260-267. doi: 10.1046/j.1365-2702.2003.00684.x

Ellis-Sloan, K. (2015). Practising care in teenage mother support groups. Critical Social Policy, 35, 535-555. doi: 10.1177/0261018315599457

Eydal, G. B., \& Kröger, T. (2010). Nordic family policies: Constructing contexts for social work with families. In H. Forsberg \& T. Kröger (Eds.), Social work and child welfare politics: Through Nordic lenses (pp. 11-27). Bristol, England: Policy Press.

Finnish Advisory Board on Research Integrity. (2009). Humanistisen, yhteiskuntatieteellisen ja käyttäytymistieteellisen tutkimuksen eettiset periaatteet ja ehdotus eettisen ennakkoarvioinnin järjestämiseksi [Ethical principles of research in the humanities and social and behavioural sciences and proposal for ordering an ethical review]. Helsinki, Finland: Finnish Advisory Board on Research Integrity. 
Finnish Advisory Board on Research Integrity. (2012). Responsible conduct of research and procedures for handling allegations of misconduct in Finland. Helsinki, Finland: Finnish Advisory Board on Research Integrity.

Friedman, M. (2013). Mommyblogs and the changing face of motherhood. Toronto, Canada: University of Toronto Press.

Gadamer, H.-G. (2013). Truth and method (2th ed.). (J. Weinsheimer \& D.G. Marshall, Trans.). London, England: Bloomsbury Academic. (Original work published 1960)

Hammer, B., Fletcher, F., \& Hibbert, A. (2017). Participant observation: Enhancing the impact measurement in community based participatory research. The Qualitative Report, 22, 439455. Retrieved from https://nsuworks.nova.edu/tqr/vol22/iss2/6

Hays, S. (1996). The cultural contradictions of motherhood. New Haven, CT: Yale University Press. Heidegger, M. (1978). Being and time. (J. Macguarrie \& E. Robinson, Trans.). Oxford, England: Blackwell. (Original work published 1927)

Husserl, E. (1982). Logical investigations (4th ed.). (J.N. Findlay, Trans.). London, England: Routledge \& Kegan Paul. (Original work published 1900)

Jorgensen, D. L. (2015). Participant observation. In R. A. Scott \& S. M. Kosslyn (Eds.), Emerging trends in the social and behavioural sciences: An interdisciplinary, searchable, and linkable resource (pp. 1-15). New York, NY: Wiley. doi: 10.1002/9781118900772.etrds0247

Julkunen, R. (2008). Kuka vastaa? Hyvinvointivaltion rajat ja julkinen vastuu [Who answers for? The limits of welfare state and public responsibility] (2th ed.). Helsinki, Finland: Sosiaali- ja terveysalan tutkimus- ja kehittämiskeskus.

Laverty, S. M. (2003). Hermeneutic phenomenology and phenomenology: A comparison of historical and methodological considerations. International Journal of Qualitative Methods, 2, 3, 2135. doi: $10.1177 / 160940690300200303$ 
MacDonald, C. L. (2010). Shadow mothers. Nannies, au pairs, and the micropolitics of mothering. Berkeley, CA: University of California Press.

Mead, S., Hilton, D., \& Curtis, L. (2001). Peer support: A theoretical perspective. Psychiatric Rehabilitation Journal, 25, 134-141. doi: 10.1037/h0095032

Miller, T. (2005). Making sense of motherhood. A narrative approach. Cambridge, England: Cambridge University Press.

Munn-Giddings, C., \& McVicar, A. (2007). Self-help groups as mutual support: What do carers value? Health and Social Care in the Community, 15, 26-34. doi: 10.1111/j.13652524.2006.00660.x

Munn-Giddings, C., Avis, M., Boyce, M., Chaudhary, S., \& Seebohm, P. (2016/17). Being a 'Selfhelp Supporter’: Recognising the roles that community practitioners can adopt in supporting self-help groups. Research, Policy and Planning, 32, 113-125. Retrieved from http://ssrg.org.uk/members/files/2016/10/Munn-Giddings-et-al.pdf

Neale, J., Tompkins, C., \& Strang, J. (2018). Qualitative exploration of relationships between peers in residential addiction treatment. Health and Social Care in the Community, 26, 39-46. doi: $10.1111 / \mathrm{hsc} .12472$

Nylund, M. (2000). Varieties of mutual support and voluntary action. A study of Finnish self-help groups and volunteers. Helsinki, Finland: The Finnish Federation for Social Welfare and Health.

Oka, T., \& Borkman, T. (2011). Self-help groups, self-help supporters, and social work: A theoretical discussion with some case illustrations of family survivors of suicide in Japan. Studies on Social Work, $\quad 37, \quad 168-183 . \quad$ Retrieved from http://pweb.sophia.ac.jp/oka/papers/2011/selfhelp/shg_ssw_201110.pdf 
Rizzo, K. M., Schiffrin, H. H., \& Liss, M. (2013). Insight into the parenthood paradox: Mental health outcomes of intensive mothering. Journal of Child \& Family Studies, 22, 614-620. doi: $10.1007 / \mathrm{s} 10826-012-9615-\mathrm{z}$

Seebohm, P., Chaudhary, S., Boyce, M., Elkan, R., Avis, M., \& Munn-Giddings, C. (2013). The contribution of self-help/mutual aid groups to mental well-being. Health and Social Care in the Community, 21, 391-401. doi: 10.1111/hsc.12021

Sihvonen, E., \& Sundsbø, A. O. (2018). Introduction: Parenting support in the Nordic countries: Is there a specific Nordic model? Social Policy \& Society, 17, 425-429. doi: $10.1017 / \mathrm{S} 1474746417000604$

Smith, R., Drennan, V., Mackenzie, A., \& Greenwood, N. (2018). Volunteer peer support and befriending for carers of people living with dementia: An exploration of volunteers' experiences. Health and Social Care in the Community, 26, 158-166. doi: 10.1111/hsc.12477

Social Welfare Act 2014 (FI). Available from https://www.finlex.fi/fi/

Solomon, P. (2004). Peer support / peer provided services: Underlying processes, benefits, and critical ingredients. Psychiatric Rehabilitation Journal, 27, 392-401. Retrieved from https://libproxy.tuni.fi/login?url=https://search.proquest.com/docview/204778995?accountid $=14242$

Health Care Act 2010 (FI). Available from https://www.finlex.fi/fi/

Tummala-Narra, P. (2009). Contemporary impingements on mothering. The American Journal of Psychoanalysis, 69, 4-21. doi: 10.1057/ajp.2008.37

Vagle, M. D. (2018). Crafting phenomenological research (2th ed.). New York, NY: Routledge.

van Manen, M. (1990). Researching lived experience: Human science for an action sensitive pedagogy. New York, NY: State University of New York Press.

Wall, G. (2010). Mothers' experiences with intensive parenting and brain development discourse. Women's Studies International Forum, 33, 253-263. doi: 10.1016/j.wsif.2010.02.019 
Watts, J. H. (2011). Ethical and practical challenges of participant observation in sensitive health research. International Journal of Social Research Methodology, 14, 301-312. doi: $10.1080 / 13645579.2010 .517658$ 


\section{Figure legends}

Figure 1. Mothers' experiences with peer support realised in a group

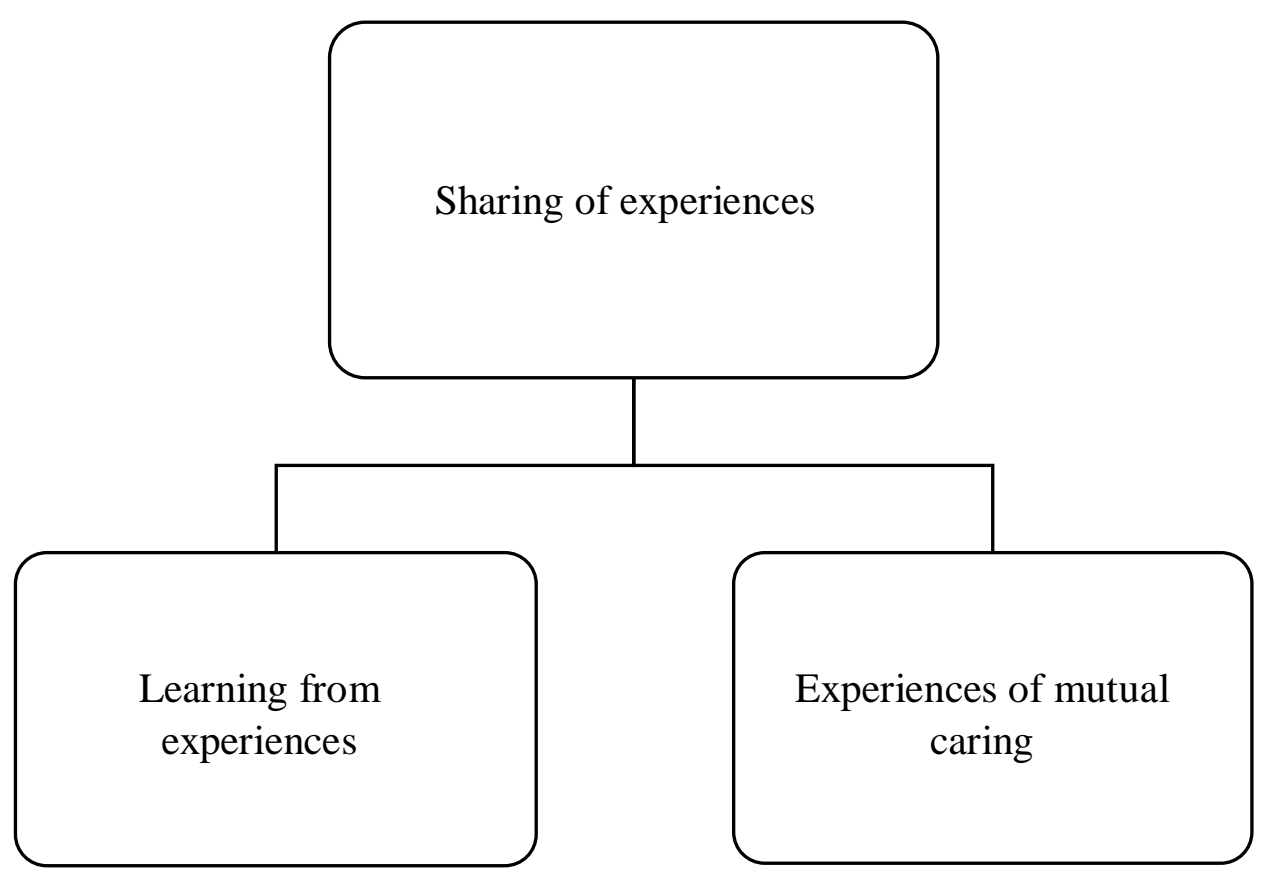

